\title{
Estudos histológico, histoquímico e ultra-estrutural de fígados e linfonodos de bovinos com presença de macrófagos espumosos ("foam cells") ${ }^{1}$
}

\author{
David Driemeier ${ }^{2}$, Severo Sales de Barros ${ }^{3}$, Paulo Vargas Peixoto ${ }^{4}$, Carlos Hubinger \\ Tokarnia $^{4}$, Jürgen Döbereiner ${ }^{4}$ e Marilene de Farias Brito ${ }^{5}$
}

\begin{abstract}
Driemeier D., Barros S.S., Peixoto P.V., Tokarnia C.H., Döbereiner J. \& Brito M.F. 1998. [Histologic, histochemical and ultrastructural study of livers and lymph nodes with foamy macrophages (foam cells).] Estudos histológico, histoquímico e ultra-estrutural de fígados e linfonodos de bovinos com presença de macrófagos espumosos ("foam cells"). Pesquisa Veterinária Brasileira 18(1):29-34. Depto Patologia Clínica Veterinária, Faculdade de Veterinária, UFRGS, Cx. Postal 15094, Porto Alegre, RS 91540-000, Brazil.

Samples of liver, kidney, spleen, and hepatic, mesenteric, retromandibular, prescapular and mediastinic lymph nodes, collected from 12 groups of cattle of different ages from the State of Mato Grosso, were studied. A total of 120 bovines was examined. According to their history, the animals were kept in pastures where Brachiaria decumbens and Brachiaria brizantha were the predominant plants. Grossly there was a yellowish liver which was more evident after $24 \mathrm{hr}$. fixation with formalin. Hepatic and mesenteric lymph nodes had normal size, however, on the cut surface there were whitish grooves, extending from the cortex to the medular, and multiple small white nodular areas in the medular. Beside these areas there were red, sometimes hemorrhagic, foci. Microscopically all animals had cells with foamy citoplasm in the liver and in the hepatic and mesenteric lymph nodes, often forming multinucleated cells. In the lymph nodes these infiltrates were adjacent to necrotic, hemorrhagic areas. In the liver the foamy cells were irregularly disseminated throughout the parenchyma or formed nodules around the central vein. These cells did not stain with PAS but weakly with oil red. Ultrastructurally foamy cells and hepatocytes showed negative images of crystals involved partially or totally by membranes. Mediastinic, retromandibular and prescapular lymph nodes of the same animals showed no gross and microscopic alterations.
\end{abstract}

INDEX TERMS: Foamy macrophages, granulomatous lymphadenitis, liver lesions, Brachiaria spp, cattle.

RESUMO.- Foram examinadas amostras de fígado, rins, baço e linfonodos hepáticos, mesentéricos, retro-mandibulares, pré-escapulares e mediastínicos de 12 lotes em um total de 120 animais, envolvendo diferentes faixas etárias, todos oriun-

\footnotetext{
${ }^{1}$ Aceito para publicação em 23 de setembro de 1997.

2 Depto Patologia Clínica Veterinária, Faculdade de Veterinária, UFRGS, Cx.Postal 15094, Porto Alegre, Rio Grande do Sul 91540-000; bolsista CNPq (301076/93-6).

3 Depto Patologia UFSM, Campus Camobi, Santa Maria, RS 97119-900; Prof. Visitante CNPq na Faculdade de Veterinária, UFPel.

${ }^{4}$ Proj. Saúde Animal Embrapa/UFRRJ, Km 47, Seropédica, RJ 23851-970.

${ }^{5}$ Disciplina de Patologia Geral e Comparada, Depto Clínica Médica Veterinária, Faculdade de Agronomia e Medicina Veterinária, UFMT, Av. Fernando Correa da Costa s/nº, Coxipó da Ponte, Cuiabá, MT 78060-900.
}

dos do Estado de Mato Grosso. Os animais haviam sido mantidos em pastos onde Brachiaria decumbens e Brachiaria brizantha eram as forrageiras predominantes. Macroscopicamente o fígado desses animais mostrava coloração amarelada, mais evidente após 24 horas de fixação em formol a $10 \%$. Nos linfonodos hepáticos e mesentéricos foram evidenciadas, na superfície de corte, estriações esbranquiçadas de forma radiada na cortical e medular com pequenas áreas brancas nodulares multifocais principalmente na medular. Em muitos casos, associado com essas áreas foram vistos focos de aspecto hemorrágico. Microscopicamente foram encontradas, no fígado, linfonodos hepáticos e mesentéricos, células com citoplasma espumoso, muitas das quais multinucleadas. Nos linfonodos hepáticos e mesentéricos estes infiltrados estavam associados a áreas de necrose e hemorragia. No fi- 
gado, as células de citoplasma espumoso estavam presentes em todo parênquima, de forma irregular, geralmente formando nódulos ao redor da veia centrolobular. Estas células não se coravam pelo ácido periódico de Schiff (PAS) e apenas fracamente na coloração de gordura pelo Oil Red $O$. Na ultraestrutura as células de citoplasma espumoso apresentavam fendas, parcial ou totalmente delimitadas por membrana, que representam a imagem negativa de cristais, presentes também no citoplasma dos hepatócitos.

TERMOS DE INDEXAÇÃO: Macrófagos espumosos, linfadenite granulomatosa, lesão hepática, Brachiaria spp, bovino.

\section{INTRODUÇÃO}

Infiltração focal de macrófagos com citoplasma espumoso tem sido descrita em fígado e linfonodos de bovinos mantidos em áreas nas quais a pastagem predominante era Brachiaria spp. (Leme et al. 1988, Driemeier et al. 1996). Silva (1989) descreveu a presença de macrófagos espumosos com citoplasma periférico no fígado de bovinos e quantificou esta alteração em diferentes graus. Na microscopia eletrônica encontrou estruturas com imagem negativa de contorno semelhante a cristalóides, revestidos por membranas assemelhando-se a fagolisossomos presentes no citoplasma dos macrófagos; procurou relacionar estes achados com a "cara inchada" dos bovinos. 0 percentual de animais com macrófagos espumosos no fígado e com "cara inchada" foi de 52,2\%.

Fotossensibilização tem sido observada no Brasil como alteração importante em bovinos e ovinos mantidos em pastos de Brachiaria decumbens formados com sementes de origem australiana (Döbereiner et al. 1976). Diante do conhecimento da etiologia comprovada pelas descrições e reprodução experimental com esporidesmina produzida por Pithomyces chartarum (Mortimer \& Taylor 1962), aliado a presença de esporos de $P$. chartarum na pastagem, a fotossensibilização na época foi atribuída ao efeito tóxico do fungo.

A presença de macrófagos espumosos no fígado e órgãos linfóides (Lemos et al. 1996) e estruturas cristalóides nos ductos biliares foi observada em surtos de fotossensibilização em ovinos mantidos em pastos de Brachiaria decumbens (Graydon et al. 1991, Lemos et al. 1996).

Estruturas cristalóides nos ductos biliares associados com fotossensibilização também foram observados após ingestão de diversas outras plantas como Tribulus terrestris e Panicum spp. (Kellerman \& Coetzer 1985). Lesões hepáticas semelhantes aos casos naturais, foram reproduzidas experimentalmente através da administração de saponinas brutas extraídas de Tribulus terrestris (Kellerman et al. 1991). As estruturas cristalóides encontradas em surtos de fotossensibilização em ovinos por Panicum coloratum, são insolúveis em acetona e xilol apresentando-se refringentes ao exame microscópico de luz polarizada, porém dissolvem-se no processamento de rotina para histopatologia convencional onde o etanol é utilizado e assim raramente são vistos nos cortes histológicos como material refringente. A eliminação dos cristais através da bile é confirmada pela presença de sapogeninas esteróides isoladas a partir de cristais contidos na bile de ovinos intoxi- cados por Panicum dichotomiflorum (Holland et al. 1991). A estrutura dos cristais é a mesma das chamadas fendas de colesterol (Bridges et al. 1987). Essas alterações histológicas são atualmente atribuídas à constituintes do próprio capim denominados de sapogeninas esteróides contidas em Panicum sp. e Tribulus terrestris (Miles, 1993). Sapogeninas consideradas hepatotóxicas para camundongos foram obtidas do conteúdo ruminal de ovinos intoxicados com Brachiaria decumbens (Abdullah et al. 1992).

Por outro lado, lesões hepáticas são também encontradas associadas à esporidesmina produzida por $P$. chartarum. Uma ampla descrição das lesões agudas e crônicas produzidas experimentalmente após administração da esporidesmina em ovinos mostrou que os animais desenvolvem colangite e colecistite aguda com posterior obstrução de ductos biliares de grande e médio calibre pela inflamação (Mortimer \& Taylor 1962). Não é citada porém, a presença de estruturas cristalóides nos ductos biliares.

A incriminação da micotoxina esporidesmina, produzida por P. chartarum, como causadora de fotossensibilização na América do Sul não tem sido confirmada na maioria das vezes (Smith \& Miles 1993, Meagher et al. 1997). A ausência de esporidesmina dos isolados de $P$. chartarum de surtos de fotossensibilização aliado a baixa contagem destes esporos indica um papel importante das sapogeninas na obstrução biliar como causa de fotossensibilização (Meagher et al. 1997).

O objetivo do presente trabalho é descrever morfologicamente as lesões, sua distribuição histopatológica e a ultraestrutura de fígados, linfonodos hepáticos e mesentéricos de bovinos de matadouro e que haviam sido alimentados com Brachiaria spp.

\section{MATERIAL E MÉTODOS}

Foram coletados em matadouros no Estado de Mato Grosso fragmentos de fígado, baço, rins, linfonodos hepáticos, mesentéricos, retro-mandibulares, pré-escapulares e mediastínicos de vários lotes de bovinos adultos de ambos os sexos. Foram coletadas ao todo 120 amostras. A procedência dos animais foi obtida no setor de recebimento dos bovinos do frigorífico conforme Quadro 1.

Quadro 1. Origem e faixa etária dos lotes amostrados em matadouros no Estado de Mato Grosso

\begin{tabular}{ll}
\hline $\begin{array}{c}\text { Municípios de } \\
\text { origem do Estado } \\
\text { de Mato Grosso }\end{array}$ & $\begin{array}{c}\text { Categoria } \\
\text { dos animais }\end{array}$ \\
\hline Alto Paraguai & Vacas \\
Cáceres & Vacas \\
Jauru & Bois adultos \\
Juara & Bois adultos \\
Nova Canaã do Norte & Vacas \\
Nova Monte Verde & Bois adultos \\
Peixoto de Azevedo & Vacas \\
Poconé & Bois adultos \\
Sinop & Bois adultos \\
Terra Nova do Norte & Vacas
\end{tabular}

As coletas foram feitas em 30.8.94, 9 e 10.1.96. As amostras foram fixadas em formol tamponado a $10 \%$, processados em parafina 
e os cortes corados pelo PAS, hematoxilina-eosina (HE) e pelo Azul da Prússia. Os cortes de congelação do fígado fixados em formol foram corados pelo Oil Red O. Fragmentos de alguns linfonodos hepáticos, mesentéricos e fígado foram coletados para microscopia eletrônica, fixados em solução de glutaraldeído a $2 \%$ tamponado em cacodilato de sódio, refixados em tetróxido de ósmio a $1 \%$ e desidratados em soluções crescentes de etanol e incluídos em Epon. Os cortes semi-finos foram corados pelo azul de metileno e os ultrafinos contrastados com acetato de uranila e citrato de chumbo e examinados em microscópio eletrônico de transmissão.

\section{RESULTADOS}

Achados epidemiológicos e macroscópicos

$\mathrm{O}$ histórico dos bovinos analisados indica que todos os animais examinados eram mantidos principalmente em pastos de Brachiaria spp.
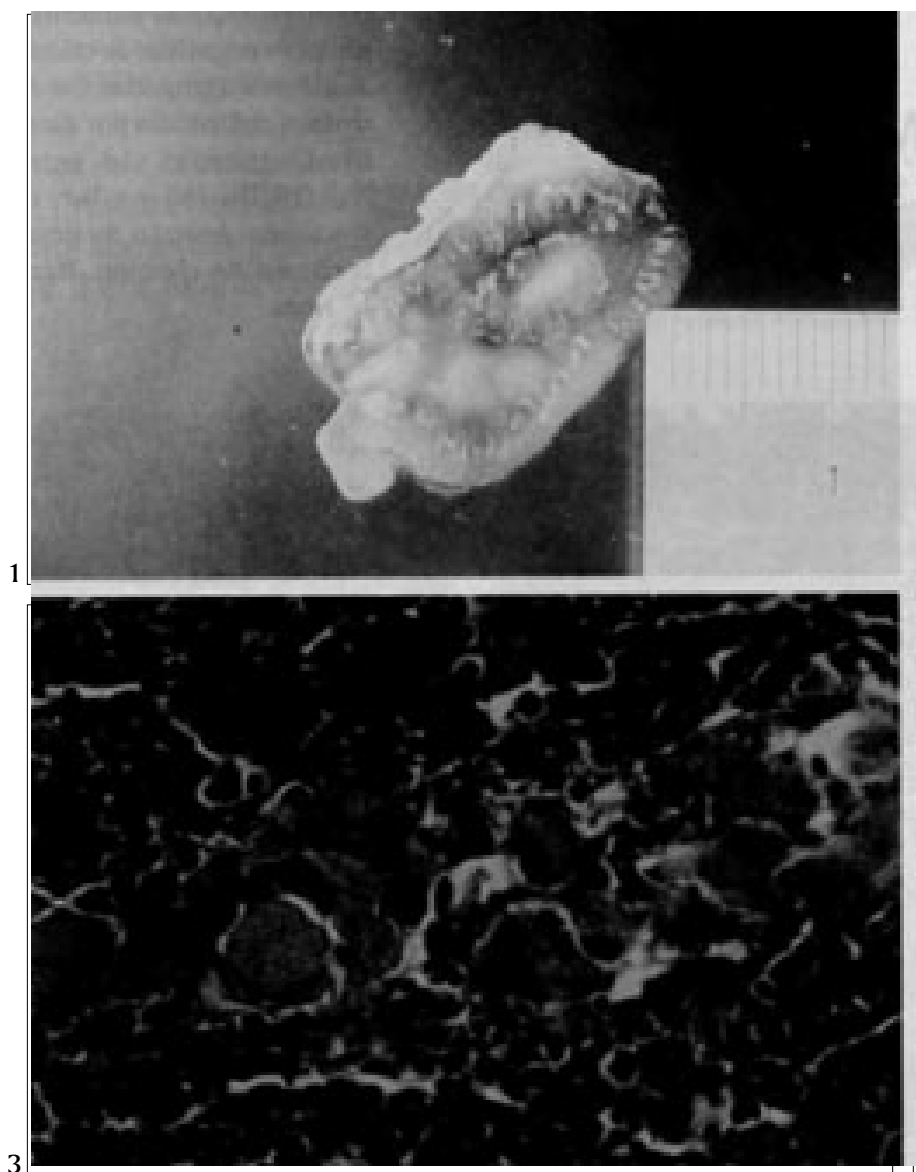

Fig. 1. Linfonodo hepático de um boi adulto mantido em pastagem de Brachiaria decumbens e $B$. brizantha, com estriações esbranquiçadas semelhantes a "giz", circundadas de áreas vermelhas resultantes da hemorragia na cortical, e uma nodulação de aspecto semelhante na medular.

Fig. 3. Linfonodo mesentérico com presença de macrófagos de citoplasma espumoso, alguns dos quais formando células gigantes. HE, obj. 40.
Macroscopicamente o fígado apresentava coloração amarelo cobre intensa que se evidenciava ainda mais após um período de 24 horas de fixação em formol a $10 \%$.

Macroscopicamente os linfonodos hepáticos e mesentéricos estavam de tamanho normal sem alterações externas. Na superfície de corte observaram-se inúmeras estriações paralelas de cor branca semelhantes a giz, dispostas em forma radiada paralela da cortical em direção à medular; alguns linfonodos apresentavam na medular pequenos nódulos brancos semelhantes aos da cortical, e que se projetavam levemente na superfície de corte (Fig. 1). Alguns animais apresentavam além disso, áreas vermelhas escuras irregulares distribuídas principalmente na cortical, por vezes intercaladas com finas estriações esbranquiçadas.

Rins e demais linfonodos não apresentaram alterações macroscópicas.
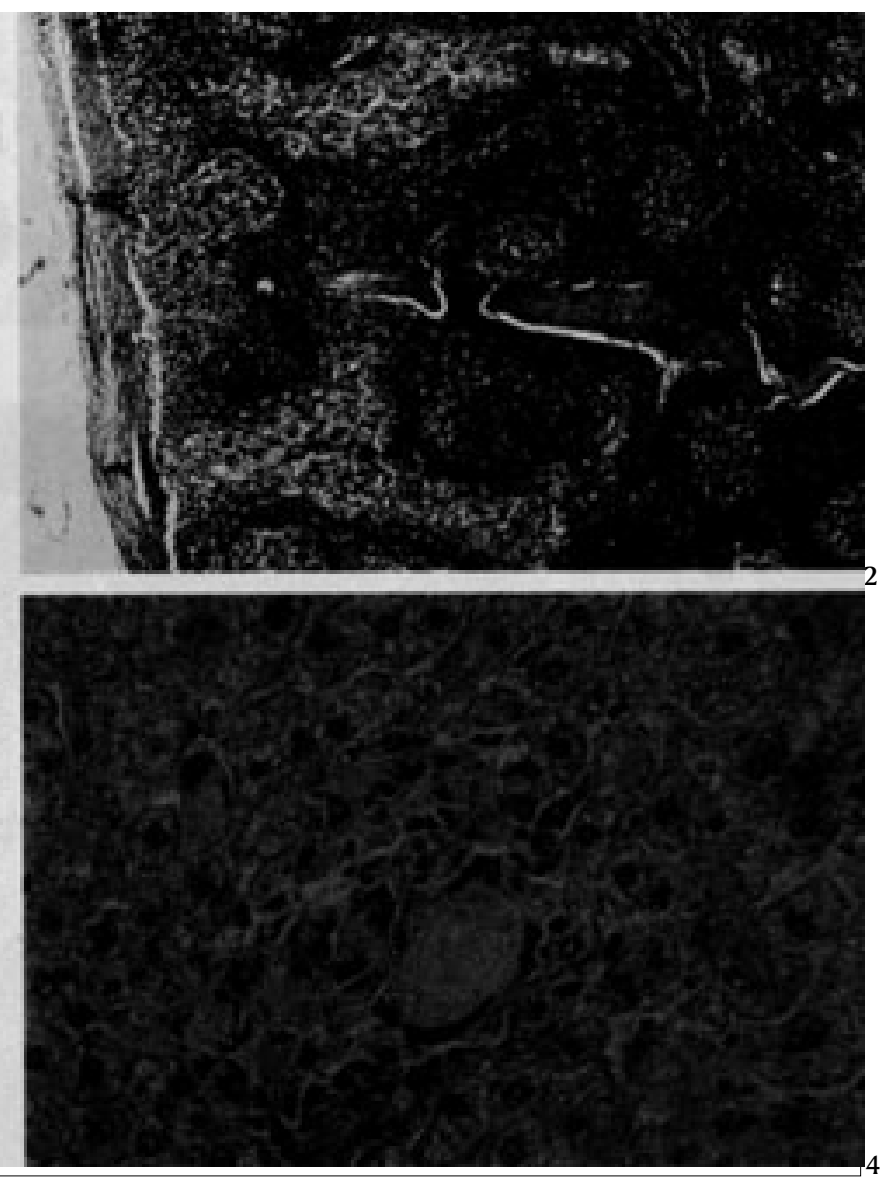

Fig. 2. Linfonodo mesentérico com infiltração das células de citoplasma espumoso nos seios linfáticos. $\mathrm{HE}$, obj. 2,5.

Fig. 4. Aglomerado de macrófagos com citoplasma espumoso no figado, com formação de células gigantes. $\mathrm{HE}$, obj. 40. 

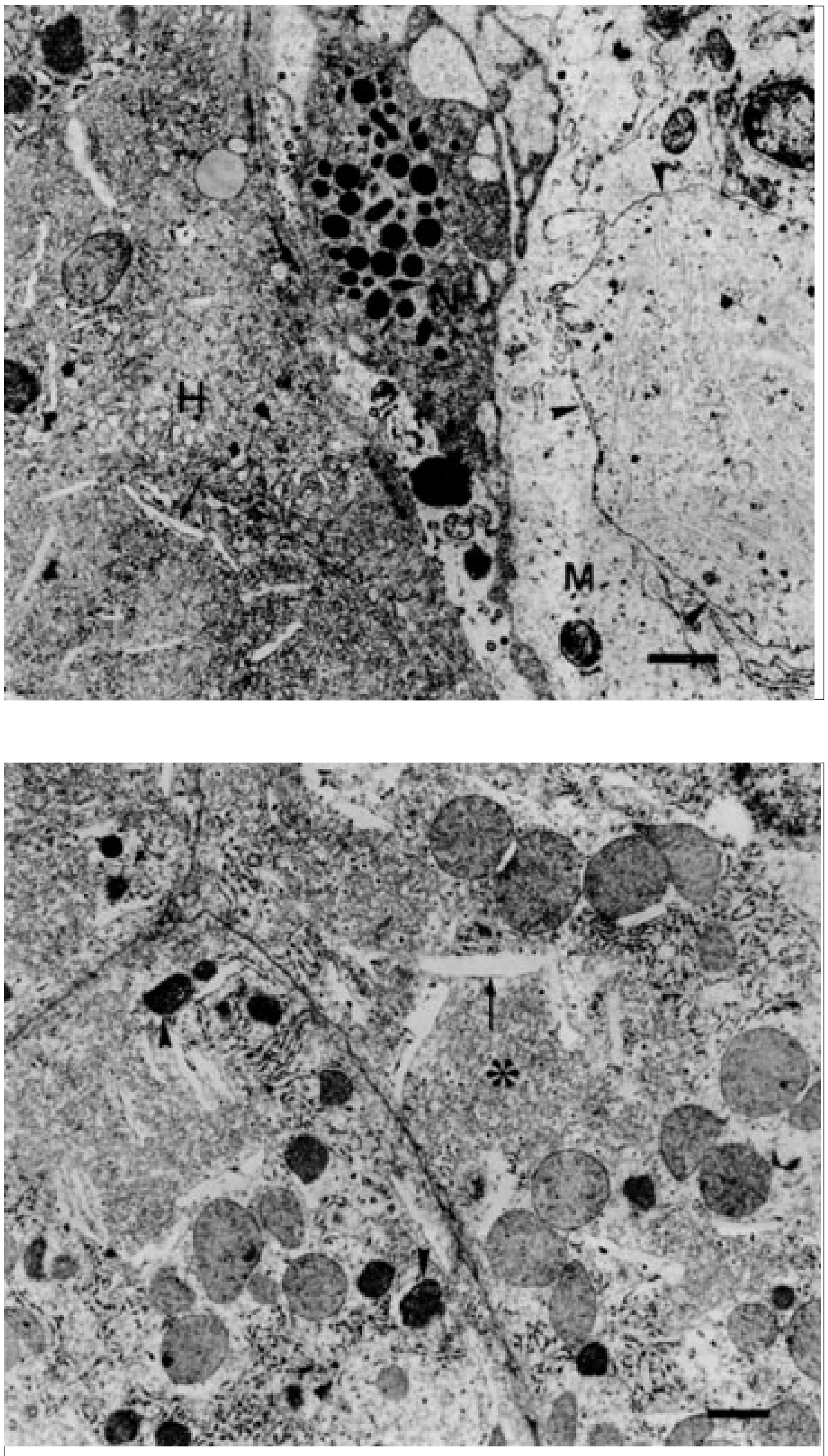

Fig. 5. Microfotografia eletrônica de fígado. Hepatócito (H). Hiperplasia do retículo endoplasmático liso. Imagem negativa de cristais aciculares no citoplasma parcialmente recobertas por membrana (seta). Macrófago (M) em íntimo contato com a luz do sinusóide, mostrando no citoplasma numerosas imagens negativas de cristais aciculares agrupadas em estrutura delimitada por membrana (pontas de seta). Neutrófilo $(\mathrm{N})$ na luz do sinusóide. Acetato de uranila-citrato de chumbo. Barra $=1 \mathrm{~mm}$.

Fig. 6. Microfotografia eletrônica de fígado. Hepatócito exibindo acentuada hiperplasia do retículo endoplasmático liso (asterisco), alguns peroxissomos (ponta da seta) e numerosas imagens negativas de cristais aciculares parcialmente delimitados por membrana (seta). Acetato de uranila-citrato de chumbo. Barra $=1 \mathrm{~mm}$. 
Achados microscópicos e ultra-estruturais

No fígado havia acúmulo de macrófagos com citoplasma espumoso que apresentavam-se sob forma de aglomerados, por vezes fusionados em células gigantes multinucleadas, distribuídas aleatoriamente no parênquima (Fig. 4), porém mais frequentes nas proximidades das veias centrolobulares. Essas células espumosas eram PAS e Oil red $\mathrm{O}$ negativas. Em todos os casos estudados, foi observada linfadenite granulomatosa dos linfonodos mesentéricos e hepáticos caracterizada pela presença de macrófagos com citoplasma espumoso (Fig. 2), muitos dos quais multinucleados e localizados nos seios linfáticos (Fig. 3). Focos de necrose com hemorragias extensas estavam associados à infiltração macrofágica. Alguns acúmulos de hemossiderina eram evidentes nos bordos dos acúmulos macrofágicos, de cor azulada na coloração pelo azul da Prússia. Os macrófagos espumosos associados aos focos de necrose com hemorragias, muitas vezes apresentavam citoplasma levemente amarelado na HE e fracamente azulado na coloração do azul da Prússia. No baço foram encontrados, apenas em dois casos, macrófagos com citoplasma espumoso. Os rins e demais linfonodos não apresentaram alterações microscópicas significativas.

O estudo ultra-estrutural do fígado, demonstrou a presença de estruturas em forma de fendas com imagem negativa, presentes nos macrófagos e hepatócitos. Nesses últimos, havia acentuada hiperplasia do retículo endoplasmático liso (Fig. 5 e 6). Muitas destas estruturas estavam delimitadas par- cial ou totalmente por membrana. Nos linfonodos hepáticos e mesentéricos foram encontrados macrófagos contendo estruturas cristalóides semelhantes às contidas nos hepatócitos. Macrófagos degenerados e/ou em necrose também foram vistos (Fig. 7). Rins e linfonodos retro-mandibulares, préescapulares e mediastínicos não apresentaram alterações.

\section{DISCUSSÃO}

Os resultados encontrados mostram que bovinos clinicamente sadios, mantidos em pastagem de Brachiaria sp podem ser portadores de lesões em linfonodos hepáticos, mesentéricos e no fígado. Estriações esbranquiçadas com áreas avermelhadas corresponderam microscopicamente e através da ultraestrutura a focos de infiltração de células fagocitárias contendo imagem negativa de estruturas cristalóides associados a necrose e hemorragias com acúmulos de hemossiderina nos linfonodos lesados. Macrófagos com citoplasma espumoso associados a hemossiderose somente foram observados nos linfonodos hepáticos e mesentéricos.

Os infiltrados de células espumosas eram sempre maiores nos linfonodos hepáticos e mesentéricos do que no parênquima hepático. Este achado deve estar ligado à absorção entero-hepática de substâncias presentes na alimentação. A natureza dessas substâncias não foi definida neste estudo. O conteúdo das células espumosas demonstrou ser apenas fracamente positivo para coloração de gordura. A

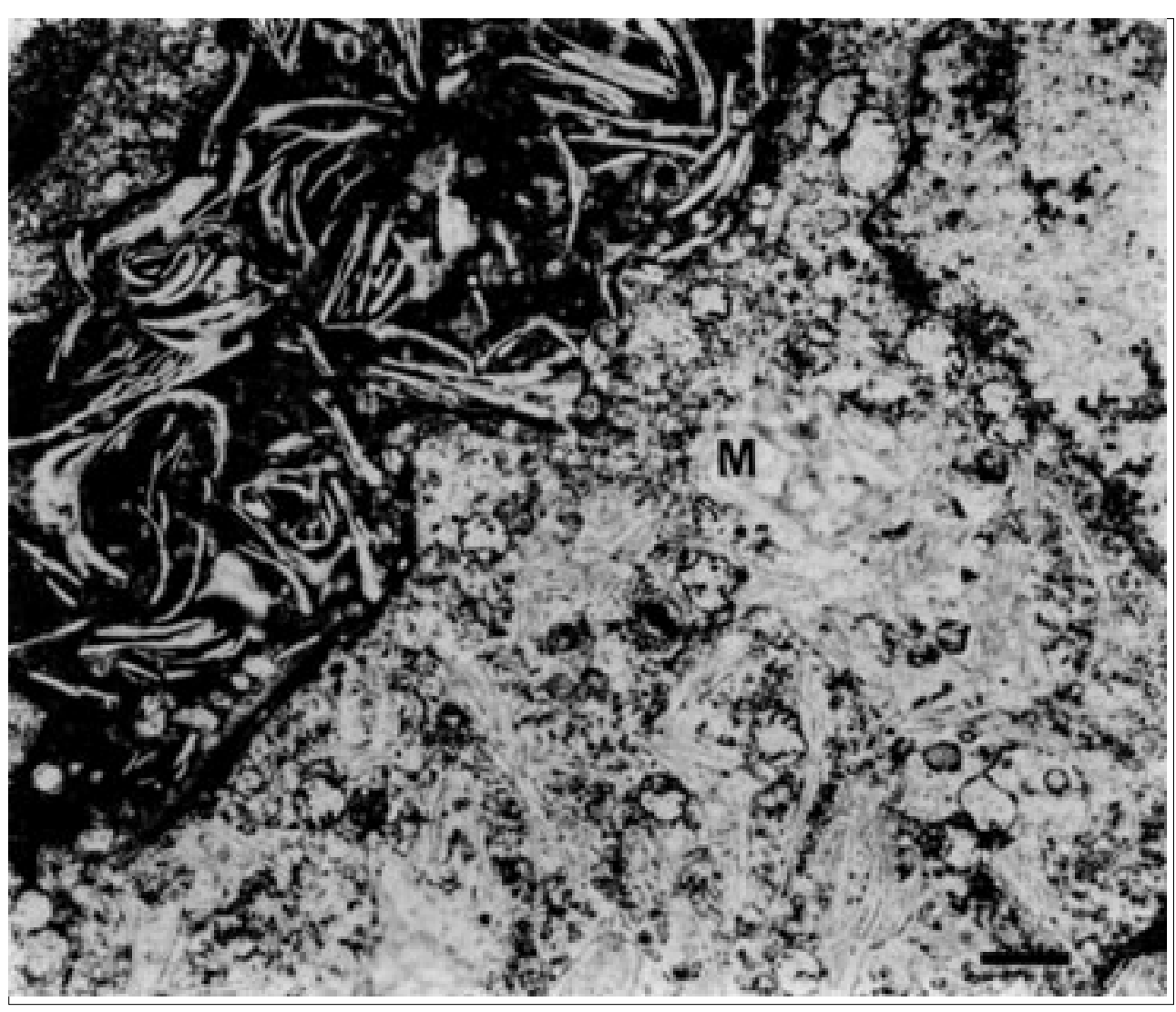

Fig. 7. Microfotografia eletrônica de linfonodo hepático. Macrófago necrótico no canto superior esquerdo, com numerosas imagens negativas de cristais aciculares no citoplasma. (M) macrófago viável mostrando estruturas cristalinas delimitadas por membrana. Acetato de uranila-citrato de chumbo. Barra $=1 \mathrm{~mm}$. 
David Driemeier et al.

imagem negativa das estruturas cristalóides indica que estas foram dissolvidas com solventes usados no processamento das amostras tanto em microscopia ótica como eletrônica; possivelmente por solventes orgânicos usados no processamento das amostras.

As alterações encontradas através dos exames histológico e ultra-estrutural deste estudo são semelhantes às descritas por aqueles autores para casos de fotossensibilização com Panicum coloratum (Bridges et al. 1987). A ausência de fotossensibilização nos animais do presente estudo pode ser devido a uma menor intensidade das lesões hepáticas. Nos fígados examinados não foram encontrados cristais e alterações mecânicas obstrutivas nos ductos biliares como os descritos por Graydon et al. (1991) e Lemos et al. (1996) em ovinos com fotossensibilização em Brachiaria decumbens.

A presença nos linfonodos mesentéricos de material cristalino no citoplasma, indica que esse material foi absorvido da alimentação e carreado aos linfonodos pela circulação linfática.

Agradecimentos.- Os autores agradecem à Denise Russowski e Silvia M. Grando, bolsistas de apoio técnico CNPq do Departamento de Patologia Universidade Federal de Santa Maria, pelo processamento do material e preparação das fotografias de microscopia eletrônica.

\section{REFERÊNCIAS}

Abdullah S.A., Lajis N.H., Bremner J.B., Davies N.W., Muastapha W. \& Rajion M.A. 1992. Hepatotoxic constituents in the rumen of Brachiaria decumbens intoxicated sheep. Vet. Hum. Toxicol. 34:154-155.

Bridges C.H., Camp B.J., Livingston C.W. \& Bailey E.M. 1987. Kleingrass (Panicum coloratum L.) poisoning in sheep. Vet. Pathol. 24:525-531.

Döbereiner J., Tokarnia C.H., Monteiro, M.C.C., Cruz L.C.H., Carvalho E. G. \& Primo A.T. 1976. Intoxicação de bovinos em pastos de Brachiaria decumbens contaminados por Pithomyces chartarum. Pesq. Agropec. Bras., Sér. Vet. 11:8794.

Driemeier D., Peixoto P.V., Tokarnia C.H., Barros S.S., Döbereiner J. \& Brito M.F. 1996. Alterações hepáticas em bovinos secundárias à ingestão de
Brachiaria spp. Anais $15^{\circ}$ Congr. Panam. Ciênc. Veterinárias, Campo Grande, MS, 21- 25 out. (Resumo)

Graydon R.J., Hamid H.H., Zahari P. \& Gardiner C. 1991. Photosensitization and crystal-associated cholangiohepatopathy in sheep grazing Brachiaria decumbens. Aust. Vet. J. 68:234-236.

Holland P. T., Miles C.O., Mortimer P.H., Wilkins A.L., Hawkes, A.D. \& Smith B.L. 1991. Isolation of the steroidal sapogenin espimilagenin from the bile of sheep affected by Panicum dichotomiflorum toxicosis. J. Agric. Food Chem 39:1963-1965.

Kellerman T.S. \& Coetzer J.A.W. 1985. Hepatogenous photosensitivity diseases in South Africa. Onderstepoort J. Vet. Res. 52(3):157-173.

Kellerman T.S., Erasmus G.L., Coetzer J.A.W., Brown J.M.M. \& Maartens B.P. 1991. Photosensitivity in South Africa. VI. The experimental induction of geeldikkop in sheep with crude steroidal saponins from Tribulus terrestris. Onderstepoort J. Vet. Res. 58:47-53.

Leme M.C..M., Mandorino I., Macruz R. \& Campedelli Filho O. 1988. Lesões degenerativas nodulares no fígado de bovinos mantidos em pastos de Brachiaria sp. no Estado de São Paulo. Arqs. Inst. Biológico, São Paulo, 55 (supl.):54.

Lemos R.A.A., Ferreira L.C.L., Silva S.M., Nakato L. \& Salvador S.C. 1996. Fotossensibilização e colangiopatia associada a cristais em ovinos em pastagem de Brachiaria decumbens. Ciência Rural, Santa Maria, 26:109-113.

Meagher L.P., Wilkins A.L., Miles C.O., Collin R.G. \& Fagliari J.J. 1996. Hepatogenous photosensitization of ruminants by Brachiaria decumbens and Panicum dichotomiflorum in the absence of sporidesmin: Lithogenic saponis may be responsible. Vet. Hum. Toxicol. 38:271-274.

Miles C.O. 1993. A role for steroidal saponins in hepatogenous photosensitisation. N. Z. Vet. J. 41:221.

Mortimer P.H. \& Taylor A. 1962. The experimental intoxication of sheep with sporidesmin, a metabolic product of Pithomyces chartarum I. Clinical observations and findings at the Post-mortem examinations. Res. Vet. Sci. 3:147-160.

Silva L.B. 1989. Alterações hepáticas em bovinos acometidos de "doença periodontal" (cara inchada). Tese de Mestrado, Universidade Federal de Minas Gerais, Belo Horizonte. 27p.

Smith B.L. \& Miles C.O. 1993. A letter to the editor: A role for Brachiaria decumbens in hepatogenous photosensitization of ruminants? Vet. Hum. Toxicol. 35:256-257. 